\title{
Dissertation on Market Disruption by Comparing with Conditions of Applying General Safeguard Measures
}

\author{
Zhuo Ren \\ International School of Jinan University \\ Guang Zhou, China
}

\begin{abstract}
Market Disruption” existing or not is the key factor to confirm whether implement the Specific Safeguard Mechanism or not for import WTO members, which are contraventions on developing countries as China. Since the relevant rules in our domestic laws are not mature, as well as the accusations and restrictions are presented frequently by the excuse of "Market Disruption", it's urgent and necessary for us to present countermeasures. In this paper through the comparison of "Market Disruption" and conditions of applying General Safeguard Mechanism, corresponding countermeasures are presented.
\end{abstract}

Keywords-Market Disruption; General Safeguard Mechanism; Specific Safeguard Mechanism

\section{INTRODUCTION}

The term "market disruption" first appeared in 1957. The true definition of the concept was at the seventeenth plenary meeting of the GATT parties in 1960. Since then, the word "market disruption" has been used frequently in the international community. First, "market disruption" was used in the short-term arrangement for cotton textiles, the long-term arrangement for 1962, and the Multi-Fiber Agreement of December 1973. Then, the developed capitalist countries led by the United States formulated and implemented special safeguard measures against the so-called "communist countries" based on the criterion of "market disruption". Such special safeguard measures had brought great obstacles to China's foreign trade export before China joined the WTO. After China's accession to the WTO, this kind of special protection measures gradually disappeared in form, but its strong pertinence and discriminatory spirit has been inherited. For our country, this is mainly reflected in China's accession to the WTO related documents. Among them, Article 16 of the Protocol of Accession of the People's Republic of China (hereinafter referred to as the Protocol of China's Accession) stipulates that the import of a product from China increases rapidly, whether absolutely or relatively, thus constituting the production of similar products or directly competitive products. An important reason for the threat of material damage or damage caused by domestic industries is the existence of market disruption.

Article 19 of GATT and the relevant provisions of the Agreement on Safeguards are hereinafter referred to as general safeguards. In general safeguard measures, the situation in which safeguard measures can be taken is not defined as a specific term, but is constrained by a series of conditions ${ }^{[1]}$. Only when these specific conditions are met can the importing Member State limit the adoption of safeguard measures. On the contrary, product-specific safeguard measures provide for the situation where special safeguard measures can be taken at the beginning, namely "market disruption" or "market disruption threat", but lack of a more detailed description of them, which will inevitably lead to the use of special safeguard measures more convenient and more targeted than the general safeguard measures ${ }^{[2]}$. Therefore, in analogy, the "market disruption" should be compared with the conditions for general safeguards.

The conditions to be applied to general safeguards can be expressed as follows:

TABLE I. GENERAL SAFEGUARD PROVISIONS

\begin{tabular}{|c|c|}
\hline $\begin{array}{c}\text { Source of } \\
\text { Law }\end{array}$ & GATT nineteenth, WTO safeguards agreement. \\
\hline $\begin{array}{c}\text { Degree of } \\
\text { Damage }\end{array}$ & Serious Injury \\
\hline $\begin{array}{l}\text { Review } \\
\text { Factors }\end{array}$ & $\begin{array}{l}\text { a) The absolute and relative growth rate and growth } \\
\text { volume of imported products. } \\
\text { b) The increased share of imported products in the } \\
\text { domestic market. } \\
\text { c) Domestic industrial output, sales level, market share, } \\
\text { productivity, equipment utilization, profit and loss, } \\
\text { employment and other indicators. } \\
\text { d) Other factors causing damage to the domestic industry. }\end{array}$ \\
\hline
\end{tabular}

(The factors of appeal inspection include all the factors of industrial damage inspection listed in Article 4, paragraph 2 (a), of the WTO Agreement on Safeguards.)

The following will be applied to the general safeguards of the substantive requirements and "market disruption" of the factors for specific analysis to understand the similarities and differences between the two.

\section{Substantive ReQuirements FOR GENERAL SAFEGUARDS.}

\section{A. A Large Increase in the Volume of Imports}

The substantial increase in import volume includes both absolute increase and relative increase. At the same time, the absolute and relative growth rate and the damage caused by growth must also be considered. For example, in the Argentine 
Footwear Safeguards Case (WT/DS121), the Appeals Chamber held that article 2, paragraph 1, and article 4, paragraph 2 (a), of the Agreement on Safeguards required not only any increase in imports, but "in such quantities under such conditions, serious damage or serious damage threat is caused $^{[3]}$. In addition, according to Article 2, paragraph 1, of the Agreement on Safeguards and Article 19, paragraph 1 (a), of GATT 1994, import growth must be rapid and rapid in a short period of time, thus causing or threatening to cause "serious harm".

\section{B. "Serious Damage" or "Serious Damage Threat"}

From the interpretation of the threat of serious injury and serious injury in Article 4 of the Agreement on Safeguards, the term "serious injury" should be understood as a significant and comprehensive reduction in the situation of a domestic industry, and the term "serious injury threat" should be understood as an obvious and imminent threat of serious injury. Obviously, any such measurement will vary from case to case, from industry to industry, and will depend on the facts of the specific case and the situation of the relevant industry. The clause requires that each of the listed factors be measured, but it does not necessarily prove that each factor is "falling". The judgment of "significant and comprehensive damage" can be made not only by the obvious decline of certain factors, but also by comprehensive analysis under the condition that each factor is not obvious. Therefore, Article 4, paragraph 2 (a), of the Safeguards Agreement requires the competent authorities to assess "all relevant objective and quantifiable factors affecting the state of the industry".

\section{Causal Relationship between Import Growth and Serious Damage Threats}

Article 4, paragraph 2 (b), of the Agreement on Safeguards provides that "when, at the same time, damage to domestic industries is caused by factors other than import growth, such damage shall not be attributed to import growth". From this we can see that not only should we make a single comparison between "import growth" and the threat of serious damage or damage, but also put other necessary reasons into it to see if it is the "main reason", "major reason" and "substantial reason", so as to judge the causal relationship between them ${ }^{[4]}$.

\section{INVESTIGATION FACTORS OF MARKET DisRUPTION}

\section{A. "Substantial Damage" or "Threat of Material Harm"}

The precondition for implementing transitional productspecific safeguards is "market disruption" or "trade transfer", which is lower than the requirement for implementing general safeguards. Paragraph 4 of the Protocol on China's Accession stipulates that "market disruption occurs when an imported product, which is the same as or directly competes with the products produced by the domestic industry, increases rapidly, absolutely or relatively, and thus becomes an important cause of material damage or threat of material damage to the domestic industry." It can be seen that China's Accession Protocol is based on the concept of "material damage" or "threat of material damage" to determine the "market disruption". However, there is no further definition of substantial damages in China's Accession Protocol.

The concept of "substantial damage" is literally the same as that used in the Anti-Dumping Agreement in respect of material damage or threat of material damage. Obviously, the degree of damage required by the "material damage" in the Anti-dumping Agreement against unfair trade is lower than that required by the "serious damage" in the Agreement on Safeguards against Fair Trade. From the case of special protection measures for bearing brakes in the United States, the U.S. investigative authorities are investigating whether imports of bearing brakes from China have caused "substantial damage" to related industries in the United States. Compared with the general criterion of damage determination of safeguards - "serious damage", it is obvious that the concept of "substantial damage" or "threat of material damage" applied in "market disruption" makes the threshold of application of special safeguards much lower ${ }^{[5]}$.

In addition, the "trade transfer" clause of Article 16, paragraph 8, of the Protocol of China's Accession also stipulates that if a product exported by China to a Member Party is deemed to cause the foregoing "market disruption" and is restricted by that Member Party, and if the product is exported to another Member Party and the growth occurs, the other Member Party will do so. There is no need to identify "market disruption" as long as it proves a "significant trade transfer" to the other member's market. There is no doubt that such a provision has wider application space for "market disruption".

\section{B. Unidirectional Applicability of "Market Disruption"}

Article 2, paragraph 2, of the Agreement on Safeguards clearly stipulates that "Safeguards for a product shall be implemented irrespective of the source of its import." This shows that although safeguards are exceptions to free trade, they still follow the basic principles of the WTO: the mostfavored-nation principle or the principle of non-discrimination, that is, safeguards are applied equally to all countries regardless of the source of their products. This was also the result of a long struggle between Brazil and other developing countries, which united small and medium-sized countries with a few developed countries, mainly the European Community, at that time $^{[6]}$. The first paragraph of the sixteenth article of China's Accession Protocol stipulates: "products such as those originating in China..." It means that any WTO member can choose to apply special safeguard measures for Chinese products in the case of "market disruption" or "market disruption threat". On the contrary, because the "market disruption" rules only aim at China's one-way provisions, China can not return a tooth for a tooth in international trade in the same way. It has led to the imbalance of rights and obligations under this rule in China.

\section{No Import Share Limit}

The Ninth Section of the safeguards agreement specifies the preferential treatment for developing country members. Article 9 , paragraph 1 , provides that if the proportion of products originating in a developing country to the total import volume of the importing Member of the product does not exceed 3 
percent, the importing member shall not take safeguards against the products originating in that developing country; however, if the share of the import does not exceed 3 percent, the import share of the developing country member shall not exceed 3 percent. A total of more than nine percent can guarantee the products of the developing countries. However, according to the provisions of Article 16, paragraph 1, of the Protocol on China's Accession to the WTO, a WTO member may take safeguards only against Chinese products, but does not stipulate that when examining whether it constitutes a "market disruption" or a "threat of market disruption", consideration should be given to whether the products exported by China account for more than $3 \%$ of the imports of that member. This not only greatly increases the possibility of the establishment of "market disruption" or "market disruption threat", but also deprives China of the opportunity to enjoy the special treatment of developing countries in this field.

\section{Duration to Prevent or Remedy Market Disruption.}

Article 16, paragraph 6 of the Protocol on China's Accession to the WTO stipulates that "a WTO Member shall take measures in accordance with this Article only within the period required to prevent or remedy market disruption. If a measure is taken as a result of a relative increase in the level of imports and continues to be in force for more than two years, China has the right to suspend the implementation of substantially equal tariff concessions or obligations under GATT1994 with respect to WTO members that have taken such measures. If absolute growth is achieved, the time limit will be 3 years. ${ }^{[7]}$ In fact, Article 16, paragraph 6 , of the Protocol on China's Accession extends the period of compensation to China to 2-3 years later. According to paragraph 246 (f) of the report of the Working Group, the application period of the measure (i.e. 2-3 years of Article 16, paragraph 6, of the Protocol of China's Accession) can be extended, provided that the competent authorities of the importing WTO member determine that "such action is necessary to prevent or remedy market disruption". This indicates that the period of 2-3 years is largely empty. If the importing country wants to extend the period of application of the measure, it only needs to perform the re-identification procedure once more when the period of 2-3 years expires. However, according to the WTO Agreement on Safeguards, the exporting country has the right to retaliate at any time after the safeguards come into force, and even to retaliate immediately. Therefore, such an arrangement not only deprives China of the right to retaliate at any time as a general WTO member, but also substantially weakens China's right to take retaliatory measures.

\section{COUNTERMEASURES TO DEAL WITH MARKET} DISRUPTION

Through the previous study, we have a clearer understanding that there are many weak links in the problem of "market disruption" in the product-specific safeguards, and it is easy to become a favorable tool for other member countries to restrict the export of our products. Faced with these situations, we are not helpless, but we can take the following measures to deal with them positively.

\section{A. Clarity of Market Disruption through Consultation and Negotiation.}

Undoubtedly, due to the vague definition of "market disruption", the provisions on product-specific safeguards have become one of the disadvantageous clauses in China's WTO accession agreements. The drawbacks are mainly reflected in the following aspects: (1) there is no widely accepted definition of "substantial damage", leaving too much room for importers to explain themselves. (2) Insufficient transparency of domestic procedures for the importer to determine the existence of "market disruption" and to adopt special safeguards. (3) Did not specify the notice and the proof procedure before confirming the "market disruption". Although the above problems are not easy to solve, we believe that consultation and negotiation will help to solve the problem ${ }^{[8]}$.This is just like before the Agreement on Safeguards was reached, the provisions of Article 19 of GATT 1947 on safeguards are not enough to deal with the problems of general safeguards. After many bilateral or multilateral agreements and negotiations, the application of general safeguards is clear and applicable. Randomness has also decreased. It can be seen from this that the imperfect rules of special safeguard measures should be perfected step by step in the framework of WTO system through consultation and negotiation.

The relevant provisions of the Protocol on China's Accession and the Report of the Working Group allow WTO members to apply completely different standards from the WTO Agreement on Safeguards when taking special measures against imports from China, and make some different arrangements in procedure. However, it should be said that the rules of special safeguard measures are exceptional clauses and are an exception to the implementation of the Agreement on Safeguard Measures. Their "particularity" has been clearly stated in the relevant statements of the Protocol and the report, while other issues such as the practical procedures, standards and time limits that have not been explicitly pointed out in the legal documents of China's accession to the WTO are not yet clear. It should be deemed to be consistent with the safeguards agreement. In the course of negotiation, we should closely link the special safeguard measures with WTO's Agreement on Safeguards, take the Agreement on Safeguards as the basis, incorporate the non-specific provisions of the special safeguard measures into the Agreement on Safeguards, and clearly apply the relevant contents of the Agreement on Safeguards stipulated by the Expert Group. The definition of the term "market disruption" clarifies the rules of "market disruption" so as to reduce the discrimination and unfairness brought about by special safeguards.

\section{B. Make Good Use of WTO Dispute Settlement Mechanism}

'Without any mention of the dispute settlement mechanism, any comment on WTO achievement is incomplete. In many ways, the dispute settlement mechanism is the main pillar of the multilateral trading system and the most unique contribution of the WTO to global economic stability ${ }^{[9]}$. Therefore, we should focus on the WTO dispute settlement mechanism, summarize a set of dispute settlement principles, procedures and methods, in the face of the "market disruption" 
problem put forward by the member states, to find the most favorable solution to safeguard China's legitimate interests.

Firstly, when facing the investigation of the safeguard measures of the importing country, the relevant export enterprises of our country should actively respond to the lawsuit and plead according to the conditions of applying the safeguard measures or special safeguard measures, so as to avoid the application of the safeguard measures of the importing country to our export products. Once the importing country has implemented the safeguard measures to our country's export products, we should seriously study and analyze the rationality of its application, and make full use of the WTO dispute settlement mechanism to counter its discriminatory or unfair practices. It should be pointed out that the WTO dispute settlement procedure and the judicial procedure of Anglo-American law have one kind of commonness, that is, attaching importance to procedural issues. Therefore, we should pay special attention to studying whether there are problems in the implementation procedures of safeguards in the importing countries.

Secondly, under the WTO dispute settlement mechanism, our appeals should be targeted. Depending on the specific circumstances of the case, we should choose whether to focus our appeal on a specific measure or on specific provisions of a domestic law. In the case of WTO precedents (including safeguards cases), if the dispute is focused on specific measures, such as issues in investigation and Adjudication procedures, the final result will be to cancel or retain a specific measure, and legislation will not be adjusted. It seems a onceand-for-all approach to require the panel of experts and the appellate body to rule on the consistency of the law if they concentrate on specific clauses, i.e. directly striking the law, but there are certain risks. The premise is that they must be sure of victory, otherwise it will only be counter-productive, but it will be further confirmed by law. The legislation of the special safeguard measures is reasonable.

\section{Establishing an Early Warning Mechanism}

Based on the "market disruption" rule, the specific product safeguard measures can be applied for up to 12 years. During this period, we have the possibility of confronting the "market disruption" problem. Therefore, on the one hand, China's largescale export enterprises should keep a high degree of vigilance and pay close attention to their exports. In the market of the importing country, we can take some precautions against the unfavorable situation. On the other hand, the competent government departments should play a good role as service providers for export enterprises, take advantage of the foresight and overall planning of the government departments, establish a set of export monitoring system with modern information means, monitor and control the main export products, and track the import and export situation of some products, especially. Closely follow up the export situation of textiles and mechanical and electrical products and the competitive situation of these products in foreign markets, and analyze and forecast the data obtained from the monitoring, especially for those products with sharp increase in quantity and large price changes. Once abnormal changes in the quantity and price of export products are found, they should be in phase in time. Related enterprises issue early warning information. At the same time, we should give full play to the coordinating role between the imports and exports chambers of Commerce and trade associations. Once the early warning information is received, the export enterprises should adjust the export rhythm rapidly under the coordination of the import and export chambers of Commerce or trade associations, so as to prevent the occurrence of dangers and resolve trade friction and disputes in the early warning stage.

\section{CONCLUSION}

Due to the vagueness of the definition of the concept of "market disruption", special protection has become a departure from the general safeguards, with considerable discrimination, unidirectionality, and inequity rules. There are many weak links in the problem of "market disruption" in the productspecific safeguard measures, and it is easy to become a favorable tool for other member countries to restrict the export of our products. We need to further study and actively respond to these problems.

\section{REFERENCES}

[1] Ye Min,Modern Economic Information, Modern economic information , 2011 (18) , pp.114-114 (In Chinese)

[2] Zhu Jiewang, Zhan Jin, Research on the Function, Influencing Factors and Guarantee Measures of Open Innovation Knowledge Synergy in Zhangjing Enterprises 2017 , 37 (1) , pp. 25-30 (In Chinese)

[3] Li Yi, "Market Disruption" and Abuse of Special Safeguard Measures in China, International Economic and trade exploration 2010 fifth issue, pp. 62-67 (In Chinese)

[4] Sun He, Zhu Zhongdi, WTO comparative analysis of various safeguards and its impact on Chin, 2005 (2), pp. 26-30 (In Chinese)

[5] Xiong Zhijian, Gao Yongfu. Interpretation and Evaluation of "Special Protection Measures" Related to Chinese Textiles. International Business Studies (Journal of Shanghai Institute of Foreign Trade), 2004,03, pp. 45-51. (In Chinese)

[6] Chen Lihu, research on the implementation of WTO safeguards for regional trade members, 2005 , 27 (6) , pp.156-163 (In Chinese)

[7] Pu Hua Lin. Analyzing the new characteristics of Sino US trade friction after China's entry into WTO. 2004, 07, pp.7-9. (In Chinese)

[8] Bajiras Ral Das, Translated by Liu Gang. Summary of WTO Agreements, Beijing: Law Press, 2000.

[9] Economic times commentator. Why trade protectionism will rise. China Economic Times, 2001-5-23 (In Chinese) 